\title{
A CYBERNETIC MODEL TO ENHANCE ORGANIZATIONAL INTELLIGENCE
}

\author{
MARKUS SCHWANINGER* \\ University of St. Gallen, CH 9000, St. Gallen, Switzerland, and Instituto Universitario de \\ Ciencias y Tecnologías Cibernéticas, Universidad de Las Palmas de Gran Canaria, \\ Campus de Tafira, E35017, Las Palmas, Spain
}

(Received 22 May 2001)

\begin{abstract}
The present paper focuses on the modeling of cognitive processes in organizations. This issue is approached from the perspective of Organizational Cybernetics, the science of control and communication applied to the management of organizations. First, the Team Syntegrity Model is described, which provides a structural architecture for processes of planning, knowledge generation and innovation in turbulent environments. The model is holographic and based on the mathematical structure of polyhedra. Then, by means of a case study it is expounded how processes of self-organization and self-reference can be designed in new, more effective ways. Finally, it is shown that the outstanding performance of this model hinges on invariant features linked to the optimal fractal dimensionality of its structure.
\end{abstract}

Keywords: Organizational cognition; Self-organization; Self-reference; Team Syntegrity; Optimal structure

\section{INTRODUCTION}

Cognition and consciousness are not completely new subjects for organizational research, but they have been underestimated, underdeveloped, and altogether underrepresented in the work of pertinent theoreticians and all the more of practitioners.

Management is, in principle, an interdisciplinary issue, and it has not only capitalized on economic theories, but also on sociology, psychology and social psychology. Microeconomics is very much at the core of domains such as finance, operations research, and theories of the firm. Sociology has very much influenced the political perspective of organization theory, dealing with the issues of power, conflict and cooperation. Psychology has entered the field of human resources management and leadership. And finally, social psychology maintains a great impact on the research about team building, group dynamics, and organizational culture.

There have been contributions about themes such as "The Mind of the Organization" [21], "The Thinking Organization" [34], "Organizational Knowledge" [25], "Organizational Memory" [40] and "Organizational Epistemology" [39]. But

*E-mail: markus.schwaninger@unisg.ch 
altogether, the potential gain which cognitive science could contribute to management although it would be enormous - has been hardly recognized up to now by the mainstream of organization science.

Yet, apart from the mainstream, there is one approach to the inquiry into and to issues of design in the organizational domain, which has built on cognitive science for a long time. It is Cybernetics - the science of communication and control in complex systems [42], and in particular management cybernetics, which is the application of cybernetic principles to organizations. The works of several originators of cybernetics, - namely Ross Ashby, Warren McCulloch, and Heinz von Foerster have had great influence on our science. Stafford Beer, the father of management cybernetics, already built on their work as early as in the fifties and sixties; see for example $[6,7,20]$. Ever since, the few management cyberneticians who exist, have tried to learn from the inquiries into cognition and consciousness. Anyway, their community has recently started to grow. Given the increasing turbulence of the socioeconomic environments, the organizational world has started to look out for better theories to orientate actors at all levels; for an overview see [14].

\section{TOWARDS INTELLIGENT ORGANIZATION}

Given the growing complexities faced by organizations of all kinds, the challenges are gigantic. Practitioners and researchers focus very much on

- Speeding up action (time management)

- Rationalizing processes (e.g. "lean management")

- Fostering quality (e.g. total quality management)

- Enhancing capabilities (e.g. process organization).

Recently, a famous firm presented itself as "strong, lean and fast". This author's immediate counter-question was "... and dumb?" Lean, fast and strong is not enough. The issue is becoming more intelligent. For example, a more intelligent way of time management would be to start earlier, instead of trying to do things faster.

The author's personal research interest has been focused on the questions, "How can organizations become more intelligent?" and "How can they maintain a high level of intelligence?"

The basic faculties that distinguish intelligent organizations are

1. To adapt, i.e. to change as a function of external stimuli;

2. To influence and shape their environment;

3. If necessary, to find a new milieu, or to reconfigure themselves anew with their environment;

4. To make a significant contribution to the viability and development of the larger wholes in which they are embedded.

These faculties are associated with processes such as "adaptation", "learning", "development", and "(self-) transformation". Here, Organizational Cybernetics has a lot to contribute. While much of the original work in cybernetics was focused on external control, management cyberneticians have emphasized the issues of cognition, self-organization and self-reference for at least three decades, by now. The inquiry 
into these crucial aspects has bred models for the design of organizations, which can dramatically improve organizational life, in the future.

\section{ON THE CONCEPTS OF ORGANIZATIONAL COGNITION, SELF-ORGANIZATION AND SELF-REFERENCE}

The cognition of an organization is the key to its intelligence. Derived from the Latin term 'cognoscere', it denotes the generation and the use of knowledge. This involves activities such as observation, perception, memorization, explanation and generalization. Perhaps 'cognoscere' originated from the Greek 'gnomon', - the shadow-casting pole of a sundial, which measures the heavens from shadows [19, p. 149].

The concept of self-organization and related phenomena has been around for a long time under different denotations:

- The biologist Roux talked about "self-regulation" in 1914 [26].

- Friedrich von Hayek, nobel laureate of economics ascertained, about 35 years ago: "... the only possibility of transcending the capacity of individual minds is to rely on those super-personal 'self-organizing' forces which create spontaneous order"; cited in [38, p. 2].

- The French sociologist Touraine conceived societies as 'self-producing' systems [35].

- The term 'autopoesis', a Greek version of 'self-production', coined by Maturana and Varela, in a context of biological research, has become very much used in sociology and management.

- Organization scientists have talked about 'self-designing' [41], 'self-restructuring' [17], and 'self-transforming' [27] organizations.

The common denominator of these concepts is the notion of an emergence of order bred by interactions in complex dynamical systems which are operationally closed: it is a behavior displayed by autonomous units, that leads to increasing cohesiveness ("eigenbehavior") "by natural drift" [37]. Self-organization has for example been observed as a fundamental property of the human brain, and therefore, is at the core of cognitive processes, as other contributors to this volume have emphasized.

Finally, the concept of self-reference is often mixed up with the concept of selforganization, but it has a distinctive meaning, and it can be used under several aspects. The sociologist Niklas Luhmann [24] distinguishes three levels, basal self-reference, reflexivity and reflection. In the context of this paper, the latter will be emphasized. Reflection is a process apt to cope with situations which self-organization cannot handle. It relies on the higher cognitive abilities entitled to observe the thinking process itself - to reflect reflection, the reflection of reflection, and so on, in a recursive mode. These cognitive processes lie at the heart of organizational capabilities such as awareness (and self-awareness, in particular, which is at the heart of consciousness), the generation of new knowledge, foresight, and creativity.

\section{MODELS TO ENABLE ORGANIZATIONAL INTELLIGENCE}

Management Cybernetics has developed powerful theorems and models for the design of intelligent organizations. Just to name a few, the Law of Requisite Variety ("Only 
variety can absorb variety", after Ashby [3]; in the original: "Only variety can destroy variety") and the Conant/Ashby theorem ("Every good regulator of a system must be a model of that system" [12]) have an importance for all aspects of management, which is comparable to the role of the laws of thermodynamics as a basis for engineering. More specific frameworks for the design of organizations are the Viable System Model [8-10] and Team Syntegrity [11], both of which have been inspired by brain research. A growing empirical evidence including the records of this author and his colleagues all over the world in using these models are testimonies of their validity and usefulness (see [13-15,30]).

Here, the Team Syntegrity Model will be examined more closely. This is an invention by Stafford Beer [11]. The author helped him in elaborating certain aspects of the model [11, p. 51, 53-63], and since the nineties - partly with his associates - has realized several experiments as well as sociometric research to test it $[4,32,33]$.

\section{OUTLINE OF THE TEAM SYNTEGRITY MODEL}

Team Syntegrity is a future-oriented approach to the design of democratic management in the sense of the heterarchical-participative type of organization (see [28]). It is a holographic model for organizing processes of communication, in particular for the (self-) management of social systems, in a nonhierarchical fashion. Based on the structure of polyhedra it is especially suitable for realizing team-oriented structures as well as for supporting organizational cognition - processes of planning, knowledge generation and innovation in turbulent environments. In the following, the architecture of the model will be illustrated by using the structure of an icosahedron, as an example.

The formation of networks by persons at different locations, who are connected by mutual interests, is a manifestation of the information society and a structural answer to challenges of our times. An infoset is a set of individuals who share a common concern and who are in possession of pertinent information and knowledge connected with the subject, as well as motivated to tackle the shared issue. The Team Syntegrity Model (for details see [11]) supplies the structural framework for the synergetic interaction of an infoset that is intended to lead to an integration of multiple topics and perspectives. The term Syntegrity results from a combination of synergy and tensile integrity. Synergy is the condition of the properties of a whole being greater and distinct from the combined properties of its parts. Tensile integrity is the structural strength provided by tension, as opposed to compression [23].

An infoset of any size can organize itself according to the structure of a polyhedron. For a number of about 30 persons the icosahedron, the most complex of the regular, convex polyhedra, is the ideal form (Fig. 1). For different numbers of people, solutions with the help of other polyhedra are possible; (see [1,36]). Each member of the infoset is represented by one edge of the icosahedron. Each vertex corresponds to a team; in the case of the icosahedron there are 12. These are marked by different colors (symbolized by different shades of grey, in Fig. 1). Five edges lead to each vertex, therefore there are five members to each team (as players). Thus each participant as a player belongs to two different teams - those connected by the edge that represents him or her. Mrs. Red-Yellow, for instance, belongs to the teams Red and Yellow. At the same time she is acting as a critic to two other teams (for example Black and Silver, which are next 


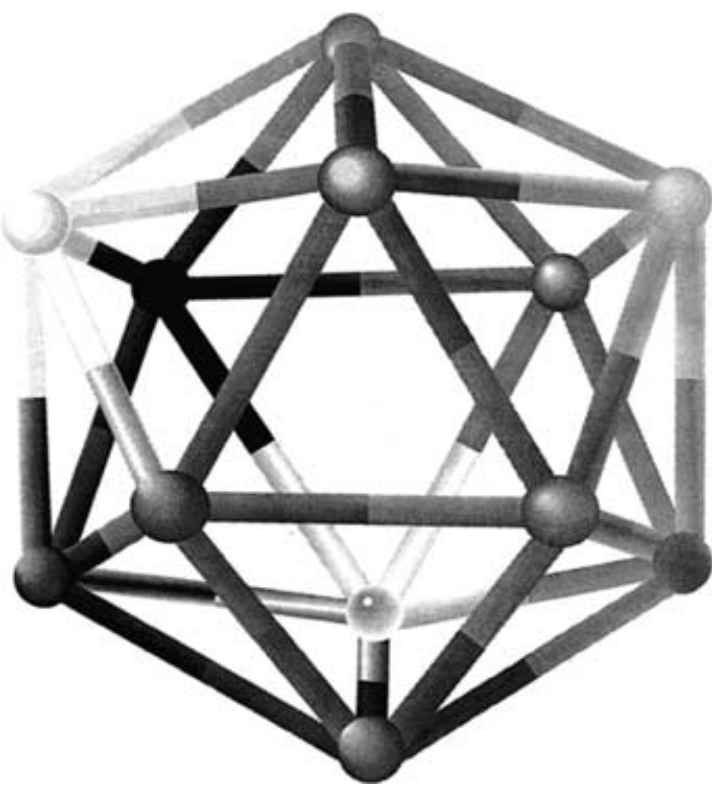

FIGURE 1 Icosahedral structure of the Team Syntegrity Model.

neighbors). This means that each team consists of five players and five critics. Altogether, the 30 actors play 120 roles.

This structure dissolves the paradox of peripherality versus centrality of actors in an organization (as formalized by Bavelas [5]): While peripherality leads to communication pathologies, alienation and low morale, centrality is needed for effective action. However, as a group grows, centrality can only be "bought" at the cost of increasing peripherality [23]. Team Syntegrity enables an infoset to acquire "centrality" via a reverberative process, although the peripherality of each one of its members equals zero, i.e., there is no peripherality at all.

A process of a syntegration has the following phases (This is a simplified representation):

1. Opening: The syntegration is dedicated to a general topic that bundles all mutual efforts and is explicated by an opening question. In syntegrations realized with students at the University of St. Gallen, the question was: "How should management education be designed in the future?"

2. Generation of the agenda ("Problem Jostle"): Each participant hands in contributions that are important to him or her (Statements of Importance). In the following steps, these are discussed and combined (Aggregated Statements of Importance). Then, in a process of successive synthesis and prioritizing, the agenda for the actual work on the general topic or problem is generated (Hexadic Reduction). This is finally expressed in 12 topics (Consolidated Statements of Importance).

3. Group Assignment ("Topic Auction"): Each member of the infoset ranks all 12 topics on a preference form. These are entered into the computer, and the membership for a topic is assigned by an optimization algorithm. An alternative would be random assignment of membership to the edges linking the vertices of the polyhedron (i.e. topics). 
Shared Information in \%

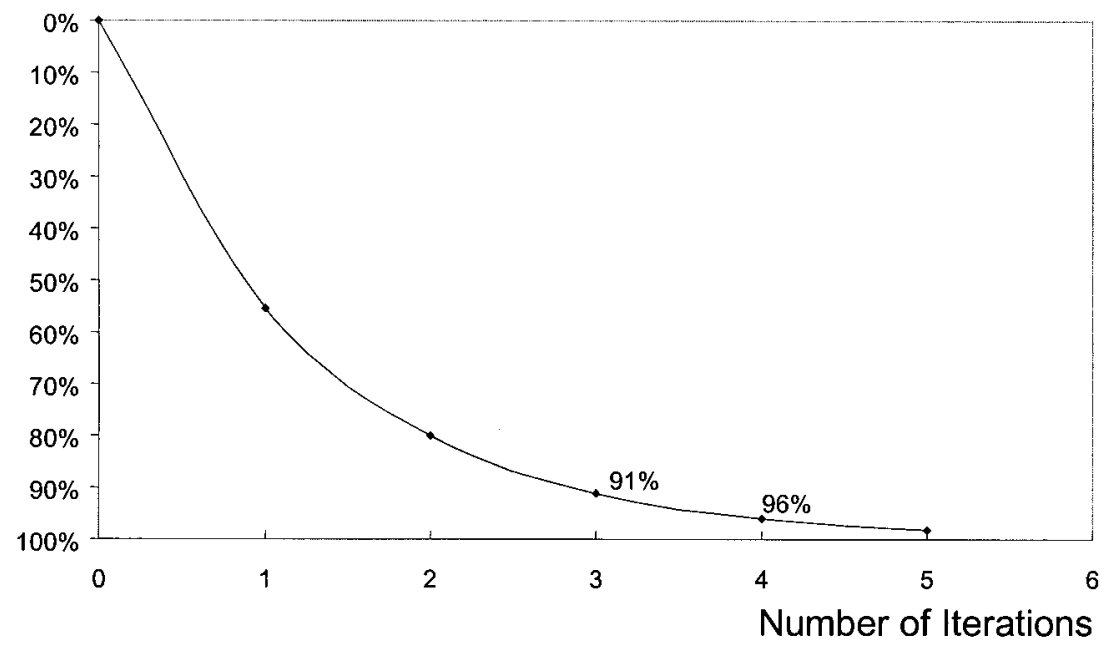

FIGURE 2 Evolution of shared information over the iterations of a Syntegrity event. Eigenvalue: $y=(1 / \sqrt{5})^{n} ; n$ is the number of iterations.

4. Working on the topic ("Outcome Resolve"): The individual teams (consisting of five players and five critics each) discuss their respective topics. Each team meets several times (usually in three iterations) and writes up a summary of its results to share with the whole infoset. The fact that the same issue in its different but interconnected aspects is continually and iteratively processed by the same set of people, who gather in alternating compositions (topic teams) implies strong reverberation. This leads to a self-organizing process with high levels of knowledge integration. There is no need for a center to integrate the multiple efforts; integration just happens "by itself". It can be shown mathematically, that this is a geometrically ergodic process, in which the eigenvalue of the process converges to a minimum: $90 \%$ of the information in the system will be shared after three iterations, and 96 after four iterations; see Fig. 2 ([see [22, p. 277]).

Sociometric studies have ascertained significant increases of different measures of cohesion between the beginning and the end of the respective syntegration events $[11,16,33]$.

5. Finalization: The teams present their conclusions in a final plenary session. Planning for subsequent action or other coordinative measures may be added as necessary.

There are specialized firms, which make Team Syntegrity available as a methodology, and support applications in all kinds of organizations, e.g. Team Syntegrity Inc., Toronto, Canada and Team Syntegrity Europe, Zurich, Switzerland. By now there have been about 150 applications, despite the young age of the Model. Team Syntegrity has been applied in the following cases, just to name a few:

- Planning processes in Universities, a polytechnical institute, and a hospital

- Organizational change in two Swiss banks

- Strategic management in several industrial firms 
- Post-merger integration

- Governmental agencies in Canada

- Regional and community planning

- Nonprofit Organizations

- Reorganization of a political organization in Great Britain

- Preparation for peace negotiations

- Ecology

- Seminars and workshops with students and researchers.

The case referred to in the following section is about the collective creation of a knowledge product. This is new and not typical yet, but this project has been chosen as a case study for two reasons. Number one, it involved the first electronic syntegration of an infoset distributed over the world. Number two, the author comanaged this difficult process, as a project of applied research, personally, from beginning to end.

\section{CASE STUDY: THE STAFFORD BEER FESTSCHRIFT PROJECT}

This is about a research project, which the author directed together with his colleague Professor Raúl Espejo (Lincoln Business School, University of Lincolnshire and Humberside, England). The project was concluded with a special event at John Moores University, Liverpool, in which we presented the result, a new CD-ROM on cybernetics applied to organization and society. This CD-ROM subsequently was also published [16]. Printouts in book format were only made for a number of libraries and individuals. One of the distinctive features of these final products lies in that they are the result of a collaborative global knowledge generation process, carried out mainly via electronic media, by 30 cyberneticians from sixteen countries and four continents. The aim of this project was to create a substantial contribution to the body of knowledge of cybernetics, which we wanted to dedicate to Stafford Beer, as a festschrift ('commemorative volume') for his seventieth birthday. A report and reflections on this project can be found in [16] and [29].

In principle, at the core of such a collective writing effort is the generation of a knowledge product. However, publications of this type often represent mere collections of articles that show little integration. Worldwide there was a reasonable number of people doing research in managerial cybernetics, and who probably would be willing to contribute. How was it possible to canalize this high potential into a coherent, integrated effort that would lead to a genuine knowledge product? In order to meet the demanding objective the project was aiming for, a new approach was required. We decided to apply the Team Syntegrity Model as a basis for organizing the process of creating the opus. This model appeared to be especially suitable for carrying out the ambitious endeavor to work on the complex domain of knowledge embodied in managerial cybernetics, in a cooperative venture uniting coauthors from all over the world.

We went about coping with the challenge confronting us, as follows:

1. Winning the cooperation of a circle ("Infoset") of experts in cybernetics (among others from the Universities of Manchester, Toronto, Valladolid, Dublin, De Los Andes/Bogotá, Mannheim, Humberside, John Moores/Liverpool, City University/ 
London, St. Gallen, Bangor, Nayang Institute of Technology/Singapore).

2. Interaction on the basis of the Team Syntegrity Model, which has already been outlined.

3. Combination of distant and local communication between the persons involved, making use of the most advanced technological means.

Up to then the Syntegrity Model had been applied in numerous strategy and organization projects, but always in workshops, i.e. via local communication. In order to enable a genuine process of generating knowledge resulting in a tangible product, the envisioned CD-ROM and book, it was required to plan and control the project in a most circumspect fashion. To get the maximal result out of the project, the first electronic syntegration ever realized was among the planned technological innovations. Another innovation was the endeavor of 30 people writing a book together, mainly via the World Wide Web.

The project went through the following phases:

\subsection{Preparation}

After a meticulous planning in early September, we installed a worldwide website as a communication platform (using a server at City University London, England, which also gave the necessary technical support).

\subsection{First Electronic Syntegration}

By way of distant interaction, the agenda for a local syntegration was generated that was to take place at the end of March in Britain. In the course of five months, an infoset of more than 40 cyberneticians from four continents and 16 countries was interacting via the Web.

At the beginning, a multitude of ideas was generated, all the participants handing in multifarious issues viewed from the most different perspectives. Later on, priorities were set successively. By means of election procedures (via World Wide Web) and lateral discussions (that were partially also carried out by supplementary means of communication such as telephone, fax, e-mail etc.) the infoset created, in self-organizing fashion, an agenda, namely the 12 topics for the various chapters of the festschrift. In this phase, 147 initial Statements of Importance were transformed, step by step, and following a complex protocol, into 12 consolidated statements of importance. This involved sophisticated techniques, such as underwriting and voting procedures via the Net (see [16]). Finally, each member of the infoset could decide to which topics he or she would prefer to contribute, i.e. which of the 12 teams he or she would join as a player. The evolution of the number of "officially counted" Statements of Importance at different levels of condensation, from Initial (147) to Aggregated (41 provisional, 35 definite) to Elided (18) and Consolidated (12), is shown in Fig. 3.

\subsection{Local Syntegration}

Towards the end of March, the definitive infoset - 30 cyberneticians - met for a three-and-half-day workshop at Mickleton near Stratford-upon-Avon, England. 


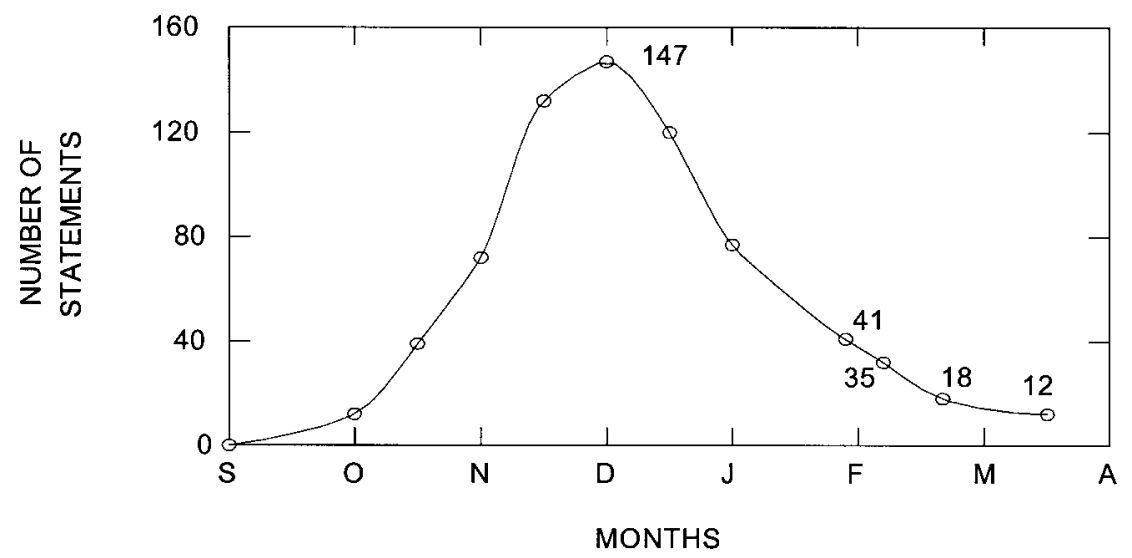

FIGURE 3 Evolution of the number of different types of Statements of Importance (Case).

An intensive, and fascinating exchange of ideas for all participants followed, as the 12 chapters of the volume were drawn up. The discussion was organized according to the geometry of an icosahedron. Each of the 30 participants was a member of two teams as a player (represented by an edge connecting two vertices of the icosahedron), as well as a critic of two further teams. Each team met in three iterations, first of all for a kind of brainstorming ("generating ideas"), the second time for a conceptualization ("modeling") and finally, the third time for designing an action plan, on how to proceed in order to produce the respective chapter within the team ("implementation"). All sessions were recorded on videotape. These recordings were then transcribed, to provide "raw material" for the write-up of our joint work. These transcripts, elaborated by Messrs. Andreas Krafft and Alfonso Reyes, are fully documented on the CD-ROM [16].

\subsection{Second Electronic Syntegration}

Again through distant interaction, the 12 chapters were written up between March and the beginning of August. For this purpose, a further platform with a special groupware ("First Class" Software) was installed on a server of the University of Bangor, Wales. An important input during this phase were the transcripts of the sessions in Mickleton. The consolidation of the chapters and the writing of one chapter reflecting on the process used by the editors, took place at the University of St. Gallen, Switzerland.

\subsection{Production of the CD-ROM}

In the months of August and September, a CD-ROM was produced at AMAZE, a multimedia company in Liverpool, England, under the direction of Mr. Roy Stringer and Dr. Roger Harnden, two multimedia experts. This CD-ROM is a technological and educational masterpiece. It documents more than merely the results of the project. Users can navigate through a hyperspace in an interactive manner, following the process that led to this end product. The contents of the 12 chapters 


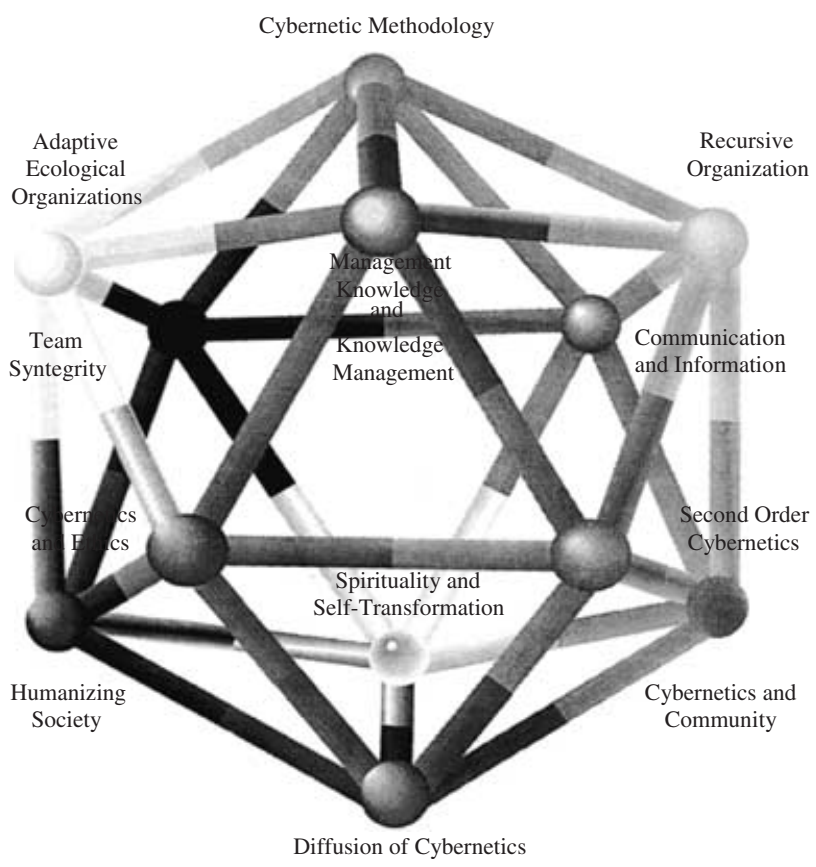

FIGURE 4 The twelve chapters of the CD and book - Overview.

will disclose to them state-of-the-art applications of cybernetics to organization and society (see overview in Fig. 4).

The presentation at John Moores University, Liverpool showed that this work constituted a world innovation. In a global, decentralized, cooperative research and publication project, more than a book and CD with 12 highly integrated chapters had been created. There was no central unit to coordinate the texts produced in the 12 teams. Coordination happened "automatically", via self-organization in a reverberative process. In the end we realized that a most promising method had been found to organize distributed processes for the elaboration of knowledge-intensive products. This way a completely new approach, whose full potential remains to be actualized in the future.

\section{CONCLUSION}

The aim of this project of applied research was examining the Team Syntegrity Model as to its aptitude for the design of virtuous self-organizing processes (Not all of self-organization is virtuous; see [2]), in particular with regard to the creation of knowledge. Given the fundamental property of organizational knowledge that is embodied in actors, the Team Syntegrity Model has proven to be a framework for this purpose, which is more powerful than the traditional ones: it provides a processoriented structure for these actors to become creative inter-actors. Interaction with a shared purpose, enabled by an ideal structure is what breeds the emergence of new knowledge. 
Team Syntegrity has a specific characteristic, which distinguishes it from more conventional approaches to face-to-face teamwork. Not only is it focused primarily on relationships rather than elements in a system. It can even enable larger numbers of people (e.g. 30, as in our case) to interact purposefully, in a nonhierarchical mode. A huge spectrum of views and insights can be brought to an intricate mode of synergetic cooperation. The process of reverberation leads to knowledge gains at three levels: individual, team and infoset. As in the case outlined, entirely new levels of knowledge can be attained. Therefore, Team Syntegrity is a powerful means of implementing the meta-system functions of management (Systems 3, 4, 5), as conceived by the Viable System Model (see [14]).

But Team Syntegrity also provides powerful structural features that warrant selfreference in the sense of self-reflection. These ensure self-awareness, and forcefully inhibit all kinds of process pathologies, which a lack of creativity and insight, but also hybris, misguided mutual assurance or miscommunication can breed at any time. (To reinforce this aspect, it is indicated to have outsiders on the infoset, who inject unorthodox and new perspectives into the process). These self-referential features operate at three levels: team, cross-team, and infoset as a whole:

(a) At the team level there are three devices: Firstly, the interaction between players involves an error-correcting mechanism, known from group-dynamics. Secondly, the critics, who are permanently present in the sessions of the Outcome Resolve are explicitly in charge of bringing a metaview into the discussion. They criticize, encourage, and embody the devil's advocate, from a content and a context as well as a process perspective. Thirdly, the groups are usually moderated by process facilitators who are the guarantors of adherence to the rules of the game (e.g. goalorientation, equality of group members, adequate participation of critics, etc.).

(b) At the cross-team level, the fact that each one of the team members is also a member of three other teams (one more as a player and two as a critic), instils self-reference into the discussion, in a natural way.

(c) At the level of the infoset as a whole, plenaries at the beginning, between the iterations, and at the end of the process, foster the emergence of a collective consciousness.

Team Syntegrity also underpins, that organizational cognition and consciousness are recursive phenomena (see [11]), which in this case, are present, distinctively, at the levels of the individual, the group and the infoset as a whole.

We have an important social invention here, which is badly needed. Our world faces regulatory crisis at many levels. Much of this crisis can be derived from obsolete concepts of organization and management, where hierarchy, autocracy and the abuse of power as an instrument of domination abound. There is an enormous potential for organizational innovation, to which this model can make a great contribution.

To conclude, it is worth mentioning that the Team Syntegrity Model still leaves questions open for exploration. On the application side, there are methodological issues concerning the detailed procedures, which have to be investigated further in different application contexts. On the theoretical side, many mathematical aspects (geometry, graph theory, topology) should be studied further. There are also promising interdisciplinary questions arising. Buckminster Fuller used to say "All systems are polyhedra". And indeed, the icosahedron represents an invariant structure, which is intriguing from a system-theoretical standpoint. Great philosophers since Plato, 
leading artists and mathematicians - namely Leonardo da Vinci and Fra Luca Pacioli were fascinated by the icosahedron. Buckminster Fuller used it as a concept for his architectural invention of the geodesic domes. A few years ago chemists discovered the icosahedron as a structure for the most enduring molecule $-\mathrm{C}_{60}-$ which was called the Buckminsterfullerene. And, finally, brain researchers have identified - without being aware of it - that the structure of the activation processes in the human brain is icosahedral [18].

Finally, it is worth noting that recent research of this author has uncovered a surprising feature. The exact dimensionality of the Team Syntegrity Model was measured, and it turned out to be exactly the same as the one exhibited by higher biological organisms. It is of the order of 2.22. The detailed account including the measurement model will be published in [32]. It has been surprising again and again, to see how effective the Team Syntegrity Model is. There seems to be no other equally powerful model that allows for deep involvement, self-organization and the emergence of collective consciousness of large numbers of people. The structural invariance addressed here had up to this point only been surmised on the grounds of analogy. Having now been uncovered as an isomorphism, it sheds some light on the causes of that effectiveness.

\section{References}

[1] A.B. Ahmad (1999). A pluralist perspective of team syntegrity: design and intervention strategy for organisational change. Ph.D. thesis, Liverpool John Moores University, Liverpool.

[2] P.M. Allen (1997). Cities and Regions as Self-organising Systems. Models of Complexity. Gordon and Breach Science Publishers, Amsterdam.

[3] W.R. Ashby (1964). An Introduction to Cybernetics. Methuen, London.

[4] U. Baer and M. Schwaninger (1998). Statistische Auswertung der im Mai 1998 an der Universität St. Gallen durchgeführten Team-Syntegrity-Veranstaltung. Report, University of St. Gallen: Institut für Betriebswirtschaft.

[5] A. Bavelas (1952). Communication patterns in problem groups. In: Cybernetics: Transactions of the Eighth Conference. Josiah Macy Foundation, New York.

[6] S. Beer (1959). Cybernetics and Management. The English Universities Press, London.

[7] S. Beer (1966). Decision and Control. Wiley, Chichester.

[8] S. Beer (1979). The Heart of Enterprise. Wiley, Chichester.

[9] S. Beer (1981). Brain of the Firm, 2nd Edn. Wiley, Chichester.

[10] S. Beer (1985). Diagnosing the System for Organizations. Wiley, Chichester.

[11] S. Beer (1994). Beyond Dispute. The Invention of Team Syntegrity. Wiley, Chichester etc.

[12] R.C. Conant and W.R. Ashby (1970). Every good regulator of a system must be a model of that system. International Journal of the System Sciences, 1(2), 89-97.

[13] R. Espejo and R. Harnden (Eds.) (1989). The Viable System Model. Interpretations and Applications of Stafford Beer's VSM. Wiley, Chichester.

[14] R. Espejo, W. Schuhmann, M. Schwaninger and U. Bilello, U. (1996). Organizational Transformation and Learning. A Cybernetic Approach to Management. Wiley, Chichester.

[15] R. Espejo and M. Schwaninger (Eds.) (1993). Organisational Fitness - Corporate Fitness through Management Cybernetics. Campus, Frankfurt/New York.

[16] R. Espejo and M. Schwaninger, (Eds.) (1998). To Be and not to Be, that is the System. A Tribute to Stafford Beer, CD ROM. Carl-Auer-Systeme Verlag, Heidelberg, ISBN 3-89670-063-4 .

[17] A. Gälweiler (1990). Strategische Unternehmensführung, 2nd Edn. Campus, Frankfurt/New York.

[18] A.P. Georgopoulos, M. Taira and A. Lukashin (1993). Cognitive neurophysiology. Science, 260(2), $47-52$.

[19] R.L. Gregory (Ed.) (1987). The Oxford Companion to the Mind. Oxford University Press, Oxford/New York.

[20] R. Harnden and A. Leonard (Eds.) (1994). How Many Grapes Went into the Wine: Stafford Beer on the Science of Holistic Management. Wiley, Chichester.

[21] A. Heirs and G. Pehrson (1982). The Mind of the Organization, revised edition. Harper \& Row, New York. 
[22] A. Jalali (1994). Reverberating networks. Modelling information propagation in syntegration by spectral analysis. In: S. Beer (Ed.) Beyond Dispute. The Invention of Team Syntegrity, pp. 263-281. Wiley, Chichester.

[23] A. Leonard (1995). Team Syntegrity: Planning for Action of the Next Century, Working Paper. TSI Inc., Toronto.

[24] N. Luhmann (1984). Soziale systeme. Grundriss Einer Allgemeinen Theorie. Suhrkamp, Frankfurt a.M.

[25] I. Nonaka and H. Takeuchi (1995). The Knowledge-Creating Company. Oxford University Press, New York.

[26] W. Roux (1914). Die Selbstregulation, ein charakteristisches und nicht notwendig vitalistisches Vermögen aller Lebewesen. Nova Acta. Deutsche Akademie der Naturforscher, Halle.

[27] M. Schwaninger (1989). Integrale Unternehmungsplanung. Campus, Frankfurt/New York.

[28] M. Schwaninger (1996). Structures for Intelligent Organizations. Discussion Paper No. 20, Institute of Management, University of St. Gallen.

[29] M. Schwaninger, (1997). Global transdisciplinary research co-operation: 30 cyberneticians online. Kybernetes, 26(4), 459-464.

[30] M. Schwaninger (2000). Managing complexity - the path toward intelligent organizations. Systemic Practice and Action Research, 13(2), 207-241.

[31] M. Schwaninger (2001). Intelligent organizations: an integrative framework. Systems Research and Behavioral Science, 18(2), 137-158.

[32] M. Schwaninger (forthcoming) Optimizing organizational fitness: a Hausdorff benchmark for complex social systems. In: R. Moreno-Díaz et al. (Eds.), Formal Methods and Tools for Computer Science. Proceedings of the EUROCAST Conference 2001. Springer, Berlin.

[33] M. Schwaninger, P. Hechenblaickner, A. Krafft and S. Steiner (1995). Research Report on the "Kingview Syntegration" July 17-20, 1995, St. Gallen, University of St. Gallen, Toronto, Canada.

[34] H.P. Sims and D.A. Gioia (1986). The Thinking Organization. Dynamics of Organizational Social Cognition. Jossey-Bass, San Francisco and London.

[35] A. Touraine (1973). Production de la société. Editions du Seuil, Paris.

[36] J. Truss, C. Cullen and A. Leonard (2000). The coherent architecture of team syntegrity ${ }^{\mathbb{B}}$ : From small to mega forms. In: J.K. Allen and J. Wilby (Eds.), Proceedings of the World Congress of the System Sciences, on CD ROM. Toronto, Canada.

[37] F. Varela (1984). Two principles for self-organization. In: H. Ulrich and G.J.B. Probst (Eds.), Self-Organization and Management of Social Systems, pp. 25-32. Springer, Berlin.

[38] H. von Foerster (1984). Principles of self-organization - in a socio-managerial context. In: H. Ulrich and G.J.B. Probst (Eds.), Self-Organization and Management of Social Systems, pp. 2-24. Springer, Berlin.

[39] G.F. von Krogh and J. Roos (1995). Organizational Epistemology. Macmillan, London.

[40] J.P. Walsh (1991). Organizational memory. Academy of Management Review, 16(1), 57-91.

[41] K. Weick (1977). Organization design: organizations as self-designing systems. Organizational Dynamics, 6(2), 30-46.

[42] N. Wiener (1948). Cybernetics or Control and Communication in the Animal and the Machine. M.I.T. Press, Cambridge, MA. 